\title{
Establishing Industry driven Business Education through Academia-Industry Interface
}

\author{
Mr. SAJITH KUMAR B ${ }^{1}$, Mr. THIMMAIAH BAYAVANDA CHINNAPPA ${ }^{2}$ \\ ${ }^{1}$ Head of the Department, People institute of management studies, Munnad, Kannur University, Kerala \\ ${ }^{2}$ Asst .professor, People institute of management studies, Munnad, Kannur University, Kerala
}

\begin{abstract}
Universities/B-Schools and industry, which for long have been operating in separate domains, are rapidly inching closer to each other to create synergies. The constantly changing management paradigms, in response to growing complexity of the business environment today have necessitated establishment of Industry orientation in Business education. Educational institutions not only contribute skilled human resources to business, but also in various intangible ways. The intersecting needs and mutually interdependent relationship requires identifying means of further strengthening academia-industry partnerships. For the above reasons, Industry rather than just being the customers of business school output today have become stakeholders and partners in progress. Industry on the other hand has also discovered the advantages of collaborative learning opportunities. Corporations seek to play increasingly important role in activities of academic institutions to incubate the talent .Business school faculty is slowly integrating the industry's views into their curriculum. Significant revisions in curriculum and contents are undertaken in business schools, with an objective of including industry recommendations. Many Business schools in India have been inviting executives from Industry to be the Academic advisors and requesting the practitioners to contribute their suggestions in framing the syllabus / updating the curriculum in order to include the topics of present day relevance in Business education. This is done with a view of imparting the knowledge and skills set, needed by graduating students in constantly changing global business environment. Corporations are placing growing emphasis on finding the "Right person". This has forced the business schools to think more carefully on whom they hire, and therefore the role of industry in the entire business school model \& industry orientation to Business education has become important.
\end{abstract}

Key Words : Business Education, Industry, Economy, Business Cycle

\section{INTRODUCTION: -}

Extremely dynamic Business world and the rapidly developing knowledge based service economy have put in an increased demand for professionals to manage the business effectively. And this is precisely the reason why amongst various other fields of knowledge, desire for acquiring Business management qualifications is growing, both amongst the fresh graduates and working executives. India has also not remained untouched with Business management degree bug and business education in India has been on a rapid rise in last one decade. In India, before the 60's, business education was not offered as a separate area of specialization. Employees in the businesses were mostly graduates or postgraduates in 'Economics' or 'Commerce' stream. In the 1960's, Business education formally started gaining importance in India with the establishment of two Indian Institute of Management; IIM Calcutta in association with Sloan School of Management and IIM Ahmedabad with Harvard Business School. After that there has been a relatively slow but steady growth in number of schools and popularity of Business education in India. A massive upsurge in the number of business schools was observed post 1991 when India was liberalized and opened to the global world. Many Multi-nationals entered India bringing with them increased demand for professionals. Business education now moved beyond the domains of government control with establishment of many private institutions/B-Schools. Indian economy was being integrated into the world economy. As any other ambitious society, India also started placing great importance on commercial activities as a catalyst to socio-economic development. Resurgent India sees wealth creation as a great equalizer amongst all sections of the society. In such a scenario a knowledge worker who can work at the cutting edge of technology, add value to the bottom-line, and provide competitive advantage to industry has become a hot commodity to acquire. In tandem with such rapidly escalating demand for business education, in year 2005, the number of business schools in India has grown to 1350 from just 130 in the year 1991, offering more than 75,000+ seats. More than $80 \%$ increase in number of business schools is coupled with increase in number of students competing for admission to the above. Each year more than 1.5 Lakh students in India compete for admission to prestigious business schools.

Though the very advent of business schools in India was to cater to the demands of the industry, the two entities have traditionally been operating in separate domains and as more or less isolated islands. There partnership is only episodic and accidental, and without any strategic intent. The trends of evolution of Business management education indicate 
that knowledge creation is becoming more students based. This will usher in a variety of changes including paradoxically a trend towards close interaction among students, industry and the faculty.

\section{IMPORTANCE OF ESTABLISHING INDUSTRY DRIVEN BUSINESS EDUCATION}

After Globalisation it is not only Educational Institutions coming forward to establish contact with Industry but it is Industrialist who have realised the major role they have to play in Educational system. It is reflected through the keen interest shown by the Confederation of Indian Industries (CII) in conducting Quality awareness programme to academic community all over the country. Many such programmes have been conducted all over the country (including Bangalore) wherein they clearly visualised without improving the Quality of Education; Industry cannot survive in the Global competition.

Today, the business schools have realized the importance of 'Industry driven Business education' for the following reasons: -

- Increasing complexity in academic and business world and constantly changing needs of the industry;

- Increasing criticality of human competence in creating and sustaining competitiveness of the organizations;

- Shift in management paradigm of business schools from earlier academic models to revenue based models.

- Growing competition for student placements and industry mind-share, with rapid increase in the number of business schools and hence the management graduates;

- Growing pressure from industry to make their fresh inductees productive from day one to reduce the subsequent training costs. Organizations today are looking for trained professionals and students capable of taking decisions. Some of the training in formative years comes out from business corporations, via collaborative internships with corporations to enhance learning opportunities to students;

- Increasing interdependence between academia and industry to satisfy need for sustenance and innovation in their respective areas.

\section{NEED FOR ACADEMIA-INDUSTRY INTERFACE IN ESTABLISHING INDUSTRY DRIVEN BUSINESS EDUCATION}

Academia- Industry Interface could be defined as "interactive and collaborative arrangement between academic institutions and business corporations for the achievement of certain mutually inclusive goals and objectives". Traditionally, business schools were looking for placements and internships for their students and the industry for fresh recruits who are well trained and equipped with the right KSA (knowledge, skills and attitude) to be able to contribute to organization's growth. Corporations are placing growing emphasis on finding the "right person". It forces the business schools to think more carefully on whom they hire, and therefore the role of industry in the entire business school model \& industry orientation to Business education becomes important.

Industry rather than just being the customers of business school output today have become stakeholders and partners in progress. Industry on the other hand has also discovered the advantages of collaborative learning opportunities. Corporations seek to play increasingly important role in activities of academic institutions to incubate the talent they need.

Aspects of Academia-industry Interface includes:

- $\quad$ Greater degree of industry-school collaboration to integrate employer's needs into the programmes on offer;

- Real involvement with industry to allow students to gain valuable practical experience and also to facilitate development of business;

- Improve the programmes by encouraging the participation of a number of guest speakers who can offer their own practical experiences;

- $\quad$ Academic staff should be encouraged to keep their skills updated by undertaking practical consultancy on regular basis.

\section{Business education}

\section{MODES OF ESTABLISHING INDUSTRY DRIVEN}

There are a number of avenues, through which Industry can orient business education. Some of the commonly used avenues are: -

1. Guest Lectures by industry representatives.

2. Suggestions in curriculum and content designing.

3. Executive Education and Management Development Programmes.

4. Joint seminars by academia and industry both for executives and students.

5. Consulting on management and related issues by academia.

6. Academia generating ideas and acting as incubators to new business.

7. Inclusion of industry experts in governing councils and other board of studies. 
International Advanced Research Journal in Science, Engineering and Technology

Vol. 8, Issue 9, September 2021

DOI: 10.17148/IARJSET.2021.8925

8. Industry providing financial and infrastructure support to business schools for their development.

9. Funding academic and applied research.

\section{GUEST LECTURES}

Guest lectures are the most popular mode of industry driven business education. Guest lectures are sessions taken up by top executives from industries in addition to classes taken up by professional teachers. The objective of this is to give students an overview of industry practices and help them relate the theory to real life applications.

\section{TRAINING AND INTERNSHIPS OF STUDENTS}

The second mode is establishing partnership through training and internships of students. This method is a self-feeding method. Industry gets a first hand feel of students in a business school, thus increasing their placement opportunities and strengthening long term relationship between the two entities. Involving industry in student training and internships has become mandatory in business curriculum in Indian business schools. All students have to spend two months with corporate working on a specific project to gain hands on experience.

\section{JOINT SEMINARS}

Joint Seminars are considered to be an effective mode of not only cross branding but also strengthening the academic relationship between business school and the industry. They are an opportunity for students to gain an understanding of the latest industry trends and industry a chance to gauge the institute and its students for prospective placements.

\section{EXECUTIVE EDUCATION}

Executive Education (long-term management training programmes for working executives) transpires preferred mode of Industry business education. There is a fundamental shift in business school offerings traditional MBA programmes to more part-time and executive education programmes. Indian Institute of Management (IIMs) has been extending their domains to executive education on modular classes to facilitate executives' involvement and strike relationship with organizations. XLRI among others have created a Partnership Model with organizations for Executive Education initiatives. Management Development Institute MDI, one of the top business schools in India was established with the prime objective of imparting management education to executives and government officials. These initiatives besides increasing the industry mind-share also fetch revenue to business schools.

\section{MANAGEMENT DEVELOPMENT PROGRAMMES (MDPs)}

Management Development Programmes (MDP) is perceived to be one of the most effective modes. MDP, though quite similar to Executive education programmes are short-duration capsule courses, which focus on a particular area or topic. Very few institutions in India are taking the necessary steps to develop the MDP network, benefiting both academia and the industry thereby resulting in industry driven business education. Business schools must therefore provide MDPs for executives either as open programs and customized company programs thereby orienting faculties to provide best in class education to their students. It should establish formal contracts with industries, which invest in their human capital through continuous or formal training.

\section{INCLUSION OF EXECUTIVES IN BOARD OF STUDIES/ACADEMIC \& GOVERNING COUNCIL}

The inclusion of executives in the Academic Councils/Governing Councils and Board of Studies in business schools is yet another preferred mode of establishing industry orientation to Business education. The objective of having industry representation is to include the latter's view in governance and other activities of business schools. Adorning these councils with the known names in industry is perceived to enhance the image and recall value of the institution, which not only attracts prospective students, donors and other stakeholders but also work in favour of business schools during ratings and rankings in imparting business education.

\section{CASE WRITING}

Case writing, which is one of the most important aspect of Industry oriented Business education. It not only adds to current knowledge pool but also enhances the learning experience of students. It serves as a benchmark study for business corporations who are either in same stage of business cycle of similar business. Innovations in management teaching can only be brought about by in-depth understanding of business processes by academicians and thought leaders. Industry, therefore has taken up an initiative of generating knowledge by funding business and academic research. CII has collaborated with many business schools to support both academic and applied research initiatives. Though this has been perceived as one of the best ways of collaboration, considerable steps have not taken up by business schools in this direction. 


\title{
International Advanced Research Journal in Science, Engineering and Technology
}

\author{
Vol. 8, Issue 9, September 2021
}

DOI: 10.17148/IARJSET.2021.8925

\section{INDUSTRY INVOLVEMENT IN FACULTY AND STUDENT SELECTION}

Industry involvement in faculty and student selection is also considered to be the preferred modes (but least preferred) of establishing Industry driven business education. Business schools have their own policy and rules on recruitment and selection of students and faculty members. Outsourcing the entire course has been perceived quite low on its effectiveness. Academicians feel that this particular mode is not able to impart the conceptual underpinnings of the issue, as practitioners tend to deal with the issue at only the practical level from their own perspectives, thus reducing the possibility of its general application across situation. Thus practitioners though bring a different perspective to the class yet do not emphasize upon understanding of basic concepts and underlying theories.

\section{CONCLUSION}

Including industry inputs has been perceived quite beneficial by business schools in improving the quality of output and making them competent of surviving in rapidly changing business environment. The business school faculty is slowly integrating the industry's views into their curriculum. Significant revisions in curriculum and contents, have undertaken in business schools, with an objective of including industry recommendations. Many business schools in India have been inviting suggestions from industry to update their curriculum and include the topics of present day relevance. This is done with a view of imparting the knowledge and skills set, needed by graduating students in constantly changing global business environment.Indian Business Schools have been traditionally using guest lectures as the most preferred medium of Industry orientation to business education. They are not only considered as a medium to establish industry networks, by giving latter an experience of institute and the students and increasing placement opportunities but also add to the learning value for students. Two-month internships are integral part of business curricula in India with certain credit assigned. This is seen as one of the best methods of giving students both the theoretical concepts and their applications and enhancing their ability to relate the two for decision-making purposeTo make industry driven business education possible Academia and Industry need to build organic relationships, with long-term strategic intent contributing to growth and development of both the entities. Business schools have to move beyond the phenomenon of 'working with employers' towards the concept of 'working with partners'. The collaboration between the two is dynamic and complex. A synergistic relationship has to be carved between the business schools and the industry so that both can benefit and also contribute to enhancing the entire teaching-learning process. However Business schools do not wish to be associated with industry on their internal issues except for imparting industry orientation to business education. Faculty \& staff selection, training and development are viewed as in-house activities, where industry's participation is not invited. Academics have been including the industry inputs into their curriculum and course designing without assessing the effectiveness of such corporate representatives to these committees. Today it is just a matter of pride for these schools to adorn their councils with big names from industry, with an objective to score high on "Industry Interface" parameter in the ratings and rankings being done by every other business magazine in India. Executives from corporates are invited to take up an entire course or few lectures with prime objective of getting them on campus for placements, but the learning, students accrue from these lectures is not evaluated.

\section{REFERENCE}

1. Abhijit Bora, Higher Education: A Few Stray Thoughts, University News, Weekly Journal Higher Association of Indian Education Universities, Vol. 49, Nov 14-20, 2011

2. Ajith Kumar K R, Karunakaran N and Thimmaiah Bayavanda Chinnappa (2021), "Repositioning Business Education for Employment and Self Employment through Content Pedagogy and Constructive Alignment of learning outcomes", Journal of Management Research and Analysis,. 8 (1): 28-31.

3. Bhattacharya P, "Technology Transfer from a Technical University: A Case Study of IIT Delhi”, Journal of Intellectual Property Rights, Vol.10, pp 413-416, 2005. http://nopr.niscair.res.in/bitstream/123456789/3681/ 1/JIPR\%2010(5)\% 20413-416.pdf

4. Bhusari R.T (2008), “Government-Industry-Academia collaboration model”, JIGYASA'08, scribd,.http:// www.scribd.com/doc/11877744/Gvernment-IndustryAcademia- Collaboration-Model.

5. Comuel, E. (2010). Are business schools to blame for the current economic crisis In From challenge to change: Business schools in the wake of financial crisis' (A compendium of essays put together by Global Foundation for Management Education) accessed from www.gfme.org/pdf/complete_web.pdf

6. Jain S.K (2007), "Increasing industry-academia collaboration", Express Pharma, 59th Indian Pharmaceutical Congress, Dec.16th 31st, 2007. http://www.expresspharmaonline.com/20071231/59thindianpharma ceuticalcongress04.shtml

7. Shetty P.K, Hiremath M.B, Murugan M, and .Sreeja K.G (2010), "Research and higher education scenario in select Indian state universities: an analysis", Indian Journal of Science and Technology, 3 (3).

8. Shwetha and Manoj Kumar (2011), "Management Education in India", Issues \& Challenges; Journal of Management \& Public Policy 3 (1):. 5-14.

9. Souvik Sen, Sourav Ganguly and Joyjeet Sen (2018)," Bridging the Industry-Academia Gap and Knowledge Management: Need of Hour", https://www.geologix.com/wp-content/uploads/2018/09/2009894.pdf

10. Thimmaiah Bayavanda Chinnappa and Karunakaran N (2021), "Human Resource Competencies and Roles in India", Journal of Management Research and Analysis, 8 (2): 101-102. 